\title{
Microstructure and Physicochemical Properties of Pericardium in Congenital Septal Heart Defects
}

\author{
Gaidash Alexsander ${ }^{1}$, Kulak Anatoly ${ }^{1}$, Krut'ko Valentina ${ }^{1}$, Musskaya Olga ${ }^{1}$, Drozdovski Konstantin ${ }^{2}$, \\ Skrotskaya Katarina ${ }^{3}$, Zamaro Alexandra ${ }^{4}$ and Kulchitsky Vladimir ${ }^{4 *}$ \\ ${ }^{1}$ Institute of General and Inorganic Chemistry, Minsk, National Academy of Sciences of Belarus, Republic of Belarus \\ ${ }^{2}$ Republican Research and Practical Center for Pediatric Surgery, Minsk, Republic of Belarus \\ ${ }^{3}$ Research Institute for Physical Chemical Problems of the Belarusian State University, Republic of Belarus \\ ${ }^{4}$ Institute of Physiology, National Academy of Sciences of Belarus, Republic of Belarus \\ *Corresponding author: Kulchitsky Vladimir, Institute of Physiology, National Academy of Sciences of Belarus, Minsk, Republic of \\ Belarus
}

\begin{tabular}{l} 
ARTICLE INFO \\
Received: April 16, 2019 \\
Published: 幽 April 22, 2019 \\
\hline Citation: Gaidash A, Kulak A, Krut'ko \\
V, Musskaya O, Kulchitsky V, et al. Mi- \\
crostructure and Physicochemical \\
Properties of Pericardium in Con- \\
genital Septal Heart Defects. Biomed \\
J Sci \& Tech Res 17(2)-2019. BJSTR. \\
MS.ID.002980.
\end{tabular}

ABSTRACT

Pericardial fragments obtained during eight open heart surgical procedures on children with atrial and/or interventricular septum defects have been investigated. Presence of clearly marked pores was established in all fragments of pericardium. The total area of original shunts was 5-6\% of pericardial samples area. Signs of pericardial calcification were revealed using physicochemical methods. It was assumed that revealed shunts serve for release (bleed) of fluid accumulated in pericardium during development of pathological processes in myocardium.

Abbreviations: ASD: Atrial Septal Defect; FTIR: Fourier Transform Infra-Red; HA: Hydroxyapatite; SEM: Scanning Electron Microscopy; VSD: Ventricular Septal Defect; XRD: X-ray Powder Diffraction

\section{Introduction}

The search for "hydropericardium", "hydropericardium, heart", "hydropericardium, heart, human", "hydropericardium, heart, children", "hydropericardium, children" revealed 311, 128, 35, 1 and 5 articles respectively, on April 06, 2019 in PubMed. Authors of one paper [1] reported death of preterm infant who died on 17th day of life due to sudden cardiac tamponade. Tamponade was caused by pericardial effusion with no obvious signs of inflammation or myocardium perforation. Hydropericardium had been forming for 8 days before death according to chest X-rays [1]. Histological examination of postmortem material revealed pericardial and interstitial edema of myocardium. Authors concluded that etiology of fatal condition and accumulation of fluid in pericardium remains unknown [1]. Fetal pericarditis usually develops due to heart failure of fetus, infections, chromosomal abnormalities, fetal anemia, intra- and extracardiac tumors [1-3]. A single case of separate hydropericardium due to left ventricle diverticulum was described [2]. There are no capillaries in pericardium and exchange of metabolites and gases is performed via diffusion. Abnormal change of pressure in heart ventricles and oncotic pressure in pericardium tissue may lead to violation of hydrodynamics at myocardium and pericardium levels. Such pathological state may be accompanied with accumulation of transudate in pericardial cavity. Therefore, pericardial properties should be studied at structural and physicochemical levels. The article focused on ultrastructural and physicochemical features of pericardium in children with congenital heart disorders.

\section{Ultrastructural Features of Pericardium in Children with Congenital Heart Disorders}

Eight biopsy samples of pericardium obtained during surgical correction of congenital septal heart defects were examined following regulatory documents and after receiving of informed consent from parents. Biopsy material was distributed into groups: first (3 samples) - atrial septal defect (ASD), second (3 samples) - ventricular septal defect (VSD), third (2 samples) - combination of ASD and VSD. Samples for scanning electron microscopy (SEM) 
were washed in $0.9 \% \mathrm{NaCl}$ solution, fixed in 3\% glutaraldehyde aqueous solution, dehydrated in increasing ethanol concentrations and coated with gold using vacuum Emitech K550X sputter coater (Quorum Technologies Ltd, UK). Electron microscopy was performed using LEO 1420 microscope combined with RÖNTEC (Germany) detector for X-ray fluorescent trace element analysis (EDAX). FTIR spectroscopy was performed using Hyperion FTIR microscope (Bruker, Germany) using 15x Gir-objective with morphological control of spectra survey points in the range of 3000 $8000 \mathrm{~cm}^{-1}$. Phase composition of air-dried samples was determined by X-ray phase analysis technique (XRD) using D8 ADVANCE diffractometer (Bruker, Germany) at CuK $\alpha=1,5405 \AA$. Dried at $60^{\circ} \mathrm{C}$ synthetic amorphized hydroxyapatite (HA) powder $\mathrm{Ca}_{10}\left(\mathrm{PO}_{4}\right)_{6}(\mathrm{OH})_{2}$ [4-7] relevant in structure and properties to mineral constituent of bone tissue was used for reference.

Clinical research techniques revealed no signs of pathological changes in pericardium of patients. However, SEM examination of pericardium samples detected special features connected with various forms of septal heart defect. There were much more pores detected in endothelial membrane of mesothelial layer (Figures 1a $\& 1$ b) together with expanded channels in intercellular matrix and destructed interstitial membranes (Figures 1c \& 1d) in samples of second (VSD) group compared with samples of first (ASD) group. XRD-halo is shifted in pericardium samples of second (VSD) group (Figure 2a) to small-angle area of angles $2 \theta$ till $21.6^{\circ}$, and for first group up to $28.9^{\circ}$. This shift indicates an ordered coarse aggregation of pericardium substance in VSD. FTIR spectra of pericardium showed a low-frequency mode shift to $3577 \mathrm{~cm}^{-1}$ in VSD (Figure 2b) $\left(3674 \mathrm{~cm}^{-1}\right.$ in ASD) in combination with regression of high-frequency side of water stretching vibrations. Mentioned parameters of infrared spectra indicate the appearance of di-, threeand multidimensional clusters of water molecules in VSD. Thermal analysis of pericardium tissue revealed decrease of water mass loss rate up to 10 and $36 \mathrm{wt} . \%$ in VSD and ASD, respectively (Figures $2 \mathrm{c} \& 2 \mathrm{~d}$ ). The temperature of organic phase destruction increased from $500^{\circ} \mathrm{C}$ for ASD to $570^{\circ} \mathrm{C}$ for VSD. Organic phase destruction consists of two stages in ASD group (Figure 2c), and one stage in VSD group (Figure 2d). The results of thermal analysis indicate that pericardium tissue in VSD is in more adhesive state than the one in ASD. Moreover, calcium phosphate is precipitated in pericardium of second group of patients. Calcium phosphate is transformed to amorphized HA in the case of combined defects (ASD+VSD) (Figure 2a curve 4), leads to lamellar bone growing. The increase in porosity of mesothelial layer and in intercellular matrix forms the structural background for hydropericardium.
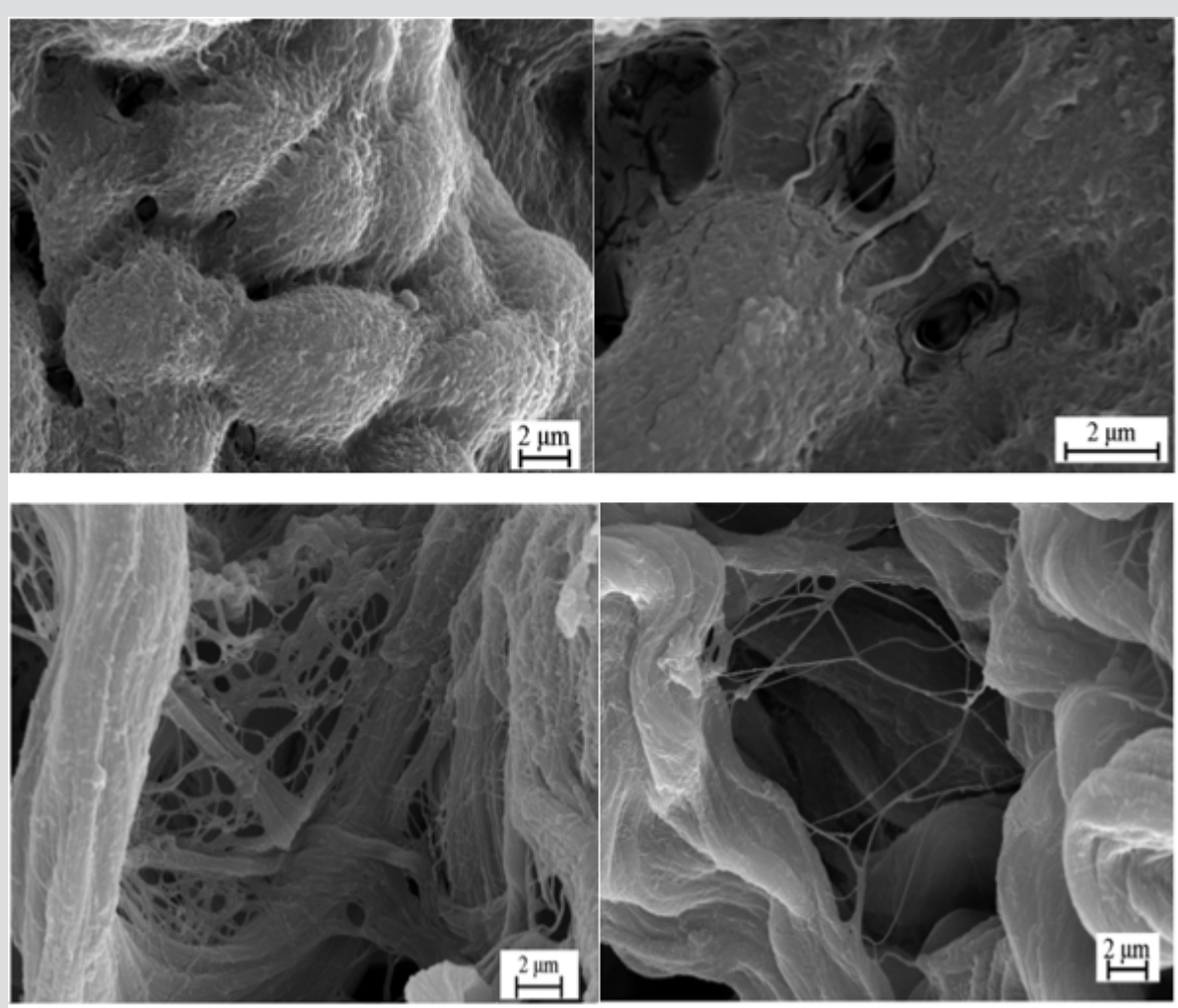

a) VSD - dilatation pores between endotheliocytes of mesothelial layer

b) VSD - dilatation pores by endothelial gateway mechanism in mesothelial layer

c) ASD - interstitial membrane of fibrous lamina mid

d) VSD - agglutination of collagen fibers in fibrous part of pericardium

Figure 1: SEM images of pericardium. 

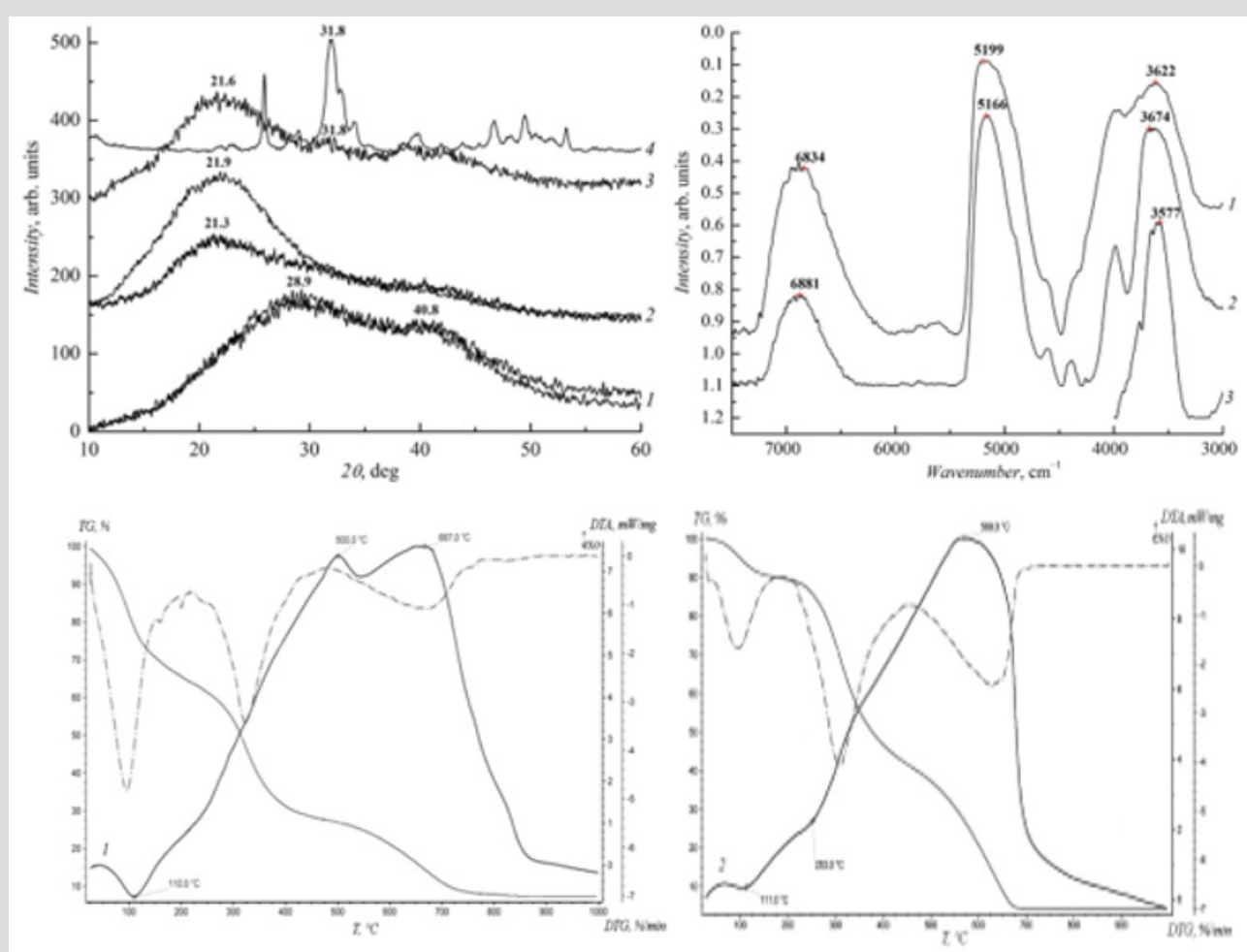
a) X-ray diffraction patterns
b) FTIR spectra
c) thermogram
d) thermogram: 1 - ASD, 2 - VSD,
3 - ASD+VSD, 4 - synthetic HA

Figure 2: Physicochemical data of pericardium.

The risk of its development is higher in combined defect (ASD+VSD) than in ASD. Physicochemical transformation of pericardium tissue in VSD has compensatory character and is aimed at equilibration of intensity and structure of hydrodynamic flows. Perhaps this happens due to formation of quasi-crystalline structures in ground substance as result of reinforcement of chemical bonds, adhesion and coupling of HA nanocrystallites. In fact, compensatory attenuation of developing random nature of tissue hydrodynamic flows happens. Pericardium tissue is subjected to viscoelastic transformation under these conditions. Elasticity of pericardium tissue will increase at early stages of pathological process development when constant alternation of increased pressure in heart ventricles in systole and decrease in diastole happens. Progression of pathological processes is accompanied with enhanced calcification of intercellular matrix. This leads to decrease of elasticity and finally to destruction of pericardial layers. Therefore, appearance of mentioned above micro fissures in mesothelial layer and around revealed pores (Figure 1b) speak for progressive decompensation process. Causes of calcification in pericardial tissue are unknown. This can be explained by hyperactivity of interstitial fibroblasts producing glycosaminoglycans and, first of all, hyaluronic acid. Structural conformations of hyaluronates are usually accompanied with formation of elastic oversaturated with water domains contacting with each other and surrounding interstitial particles. Namely domain conformations of hyaluronic acid may become key factor contributing to increase of viscosity of pericardial layers and adhesion of heterogenous molecular components of intercellular matrix in VSD.

\section{Conclusion}

Performed investigation revealed structural changes and physicochemical transformations in pericardium layers for the first time. These changes have been always out of doctors' attention. Presence of clearly marked pores was established in all fragments of pericardium. The total area of original shunts was 5-6\% of pericardial samples area. Therefore, it is necessary to expand specification of pericardium biopsy material in various heart abnormalities, including septal defects. Such strategy will decrease current prognostic uncertainty in these conditions. The main thing is that obtained data will finally become the basis for increase of effectiveness of preventive and treatment tactics of cardiologists and cardiac surgeons. Cell technologies and/or bioprinting may become one of the ways of correction of pathological processes in heart [8-12].

\section{References}

1. Stanek J, Willett GD, Lage JM (1993) Idiopathic hydropericardium as a cause of death of a preterm neonate. Pediatr Pathol 13(1): 1-8. 
2. Cesko I, Hajdú J, Csapó ZD, Tóth T, Sipos B, et al. (1998) Fetal hydropericardium associated with left ventricular diverticulum. Prenat Diagn 18(7): 721-724.

3. Niu Y, Sun Q, Liu X, Liu S (2019) Mechanism of fowl adenovirus serotype 4-induced heart damage and formation of pericardial effusion. Poult Sci 98(3): 1134-1145.

4. Tsuber VK, Lesnikovich LA, Kulak AI, Trofimova IV, Petrov PT, et al. (2006) Synthesis, identification and determination of impurities in bioactive hydroxyapatite. Pharm Chem J 40(8): 455-458.

5. Krut'ko VK, Kulak AI, Lesnikovich LA, Trofimova IV, Musskaya ON, et al (2007) Influence of the dehydration procedure on the physicochemical properties of nanocrystalline hydroxylapatite xerogel. Russ J Gen Chem 77(3): 336-342.

6. Musskaya ON, Kulak AI, Krut'ko VK, Lesnikovich YA, Kazbanov VV, et al. (2018) Preparation of Bioactive Mesoporous Calcium Phosphate Granules. Inorg Mater 54(2): 117-124.

7. Krut'ko VK, Kazbanov VV, Musskaya ON, Gaidash AA, Kulak AI, et al. (2019) Physicochemical Properties and Structure of the Bone Matrix in Simulated Tuberculous Osteitis. Techn Phys 89(1): 147-152.

\section{ISSN: 2574-1241}

DOI: 10.26717/BJSTR.2019.17.002980

Kulchitsky Vladimir. Biomed J Sci \& Tech Res

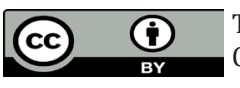

This work is licensed under Creative

Commons Attribution 4.0 License

Submission Link: https://biomedres.us/submit-manuscript.php
8. Zamaro A, Koulchitsky S, Pashkevich S, Stukach Y, Dosina M, et al. (2019) Perineural Way of Stem Cells Migration to Injured Heart Regions. Biomed J Sci \& Tech Res 14(1): 1-4.

9. Kulchitsky V, Zamaro A, Koulchitsky S (2019) Perineural Migration of Stem Cells in the Model of Damaged Heart Nodes. Biomed J Sci \& Tech Res 14(4): 1-3.

10. Kulchitsky V, Zamaro A, Krivenchuk D, Koulchitsky S (2019) Can Nerve Trunks Serve as Railroads for Stem Cells? Biomed J Sci \& Tech Res 15(1): $1-3$.

11. Zamaro A, Koulchitsky S, Ponomarenko G, Kulchitsky V (2019) Perineural Migration of Autologous Stem Cells and Their Role in The Functional Reparation of Injured Internal Organs. Biomed J Sci \& Tech Res 16(1): 1-4.

12. Zamaro A, Krivenchuk D, Denisov A, Koulchitsky S (2018) Topical Issues of Bioprinting Technology. Biomed J Sci \& Tech Res 12(1): 1-3.

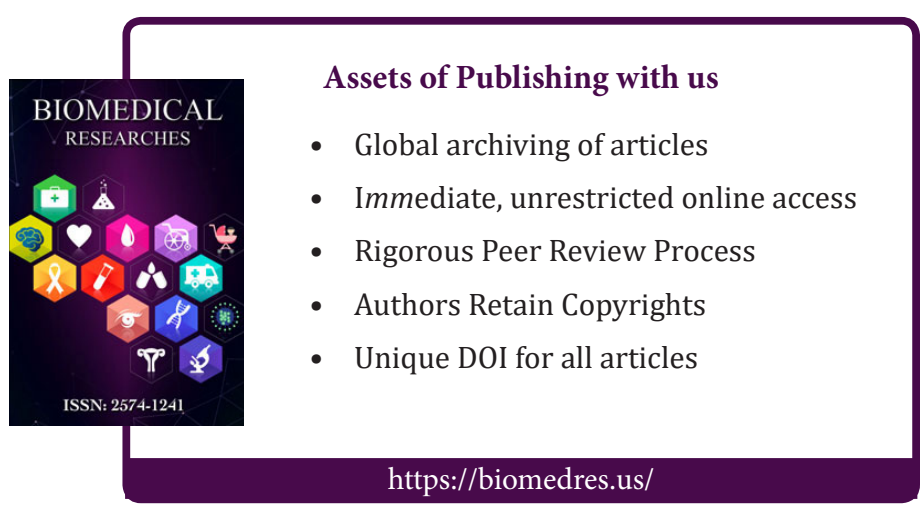

